\title{
CARACTERIZAÇÃO DO BIOCARVÃO OBTIDO A PARTIR DA PIRÓLISE DO ENDOCARPO DO COCO (COCOS NUCIFERA L.)
}

\author{
R. G. S. A. ANDRADE ${ }^{1}$, K. R. B. MELO ${ }^{1}$, J. I. SOLETTI ${ }^{1}$, S. H. V. CARVALHO ${ }^{1}$ e L. \\ MEILI $^{1}$ \\ ${ }^{1}$ Universidade Federal de Alagoas, Centro de Tecnologia (CTEC) \\ E-mail para contato: ragabiandrade@gmail.com
}

\begin{abstract}
RESUMO - A pirólise consiste na degradação da biomassa através do fornecimento de altas temperaturas na ausência de oxigênio. Ao final do processo são obtidos três produtos, biocarvão, bio-óleo e gases incondensáveis, as proporções desses variam com as condições operacionais. O material de estudo do presente trabalho foi o biocarvão do endocarpo do coco, visando sua adição ao solo para aumentar a fertilidade através da retenção de nutrientes nos poros presentes no carvão. As pirólises foram realizadas nas temperaturas de $400{ }^{\circ} \mathrm{C}$, $500{ }^{\circ} \mathrm{C}, 600{ }^{\circ} \mathrm{C}$ e $700{ }^{\circ} \mathrm{C}$, com taxa de aquecimento de $10{ }^{\circ} \mathrm{C} / \mathrm{min}$, tempo de residência de $120 \mathrm{~min}$. Em seguida, foram realizadas as análises de pH, FT-IR e análise imediata (umidade, voláteis, cinzas e carbono fixo). Pelos dados obtidos percebe-se que o rendimento dos produtos depende diretamente da temperatura utilizada, sendo o rendimento sólido favorecido em temperaturas mais baixas. Além disso, os carvões apresentaram comportamento alcalino e similaridade na composição. Desse modo, a mudança de temperatura de pirólise para uma mesma biomassa não altera significativamente a composição dos biocarvões obtidos, que em sua maioria é formada por compostos voláteis e baixos teores de cinzas e carbono fixo, que aumentam com a temperatura. Esses resultados comprovam a potencialidade da aplicação do biocarvão no aumento da qualidade do solo.
\end{abstract}

\section{INTRODUÇÃO}

\subsection{Processo de Pirólise}

Pirólise é a tecnologia de termoconversão da biomassa, através de uma programação de tempo, temperatura e atmosfera controladas, na qual são produzidos três produtos principais: sólido (biocarvão), líquido (bio-óleo) e gasoso (Alho, 2012). O tipo de reator de pirólise, os parâmetros de reação (temperatura, tempo de residência) e o tipo e as características da biomassa (tamanho de partícula, forma e estrutura) têm fortes efeitos sobre o rendimento e propriedades dos produtos formados. Dentre as variáveis, a temperatura é a mais significante porque influencia a conversão da biomassa e a distribuição de produtos (Cantrell et al., 2012). 


\subsection{Aplicação do Biocarvão}

O biocarvão, também conhecido como biochar, é um material de carbono poroso enriquecido e produzido a partir de uma variedade de biomassa. Possui diversas aplicações, mas quando adicionado ao solo agrega valor, pode aumentar a fertilidade e melhorar a qualidade do solo através da elevação do $\mathrm{pH}$, além de aumentar a capacidade de retenção de umidade e melhorar a capacidade de troca catiônica, ajudando o solo a manter os nutrientes (Hossain et al., 2011). A biomassa utilizada nas pirólises foi o endocarpo do coco, região fina e muito dura do coco.

\section{METODOLOGIA}

A unidade pirolítica utilizada possui um forno tubular JUNG modelo LT6 2010, com controlador de temperatura, taxa de aquecimento e tempo de residência. $O$ sistema de resfriamento é composto por um banho termostatizado modelo TE-184, conectado a 3 condensadores, 2 em série e 1 em paralelo, os quais estão ligados a dois kitassatos para a coleta do bio-óleo. Além disso, uma bomba de vácuo torna o meio inerte. As temperaturas utilizadas para as pirólises foram de $400{ }^{\circ} \mathrm{C}, 500^{\circ} \mathrm{C}, 600{ }^{\circ} \mathrm{C}$ e $700{ }^{\circ} \mathrm{C}$. A taxa de aquecimento, o tempo de residência e a temperatura do banho foram fixados em, $10^{\circ} \mathrm{C} / \mathrm{min}, 120$ minutos e $3{ }^{\circ} \mathrm{C}$, respectivamente. $\mathrm{O}$ endocarpo do coco foi inicialmente seco em estufa e a massa utilizada foi de 400,0 g por pirólise. Após a obtenção dos carvões foram realizadas as análises de pH, FT-IR, umidade, voláteis, cinzas e carbono fixo.

A análise de $\mathrm{pH}$ foi realizada em triplicata. Pesou-se 1,0 g de cada carvão previamente macerado, adicionando posteriormente $20 \mathrm{~mL}$ de água deionizada em cada amostra, as quais foram homogeneizadas em uma Incubadora SHAKER Solab modelo SL222 durante uma hora e meia, com rotação de $100 \mathrm{rpm}$. Em seguida, o pH foi medido com um pHmetro Marconi modelo PA 200.

A espectroscopia no infravermelho via transformada de Fourier (FT-IR) foi realizada com o equipamento FT-IR NICOLET modelo iS 10 no Laboratório de Tecnologia de Nanosistemas Carreadores de Substâncias Ativas (TecNano) na Universidade Federal de Alagoas (UFAL) e utilizou o método de transmitância, com pastilhas de $\mathrm{KBr}$ com $20 \mathrm{mg}$ de amostra e $200 \mathrm{mg}$ de $\mathrm{KBr}$, com número de onda entre $4000 \mathrm{~cm}^{-1}$ e $400 \mathrm{~cm}^{-1}$ e resolução $4 \mathrm{~cm}^{1}$.

$\mathrm{Na}$ análise imediata (umidade, voláteis, cinzas e carbono fixo) os cadinhos foram inseridos na mufla EDG modelo $\mathrm{f} 3000$ pré-aquecida a $750{ }^{\circ} \mathrm{C}$ por $10 \mathrm{~min}$. Foram adicionados em cada cadinho $1,0 \mathrm{~g}$ de amostra, os quais ficaram na mufla a $105{ }^{\circ} \mathrm{C}$ durante $2 \mathrm{~h}$. Em seguida, permaneceram a $950{ }^{\circ} \mathrm{C}$, durante $2 \mathrm{~min}$ com a porta aberta, $3 \mathrm{~min}$ com a porta aberta e no interior da mufla, e 6 min com a porta fechada. Por fim, os cadinhos ficaram durante $6 \mathrm{~h}$ na mufla a $750{ }^{\circ} \mathrm{C}$. As análises foram realizadas em duplicata. Ao final de cada etapa os cadinhos foram colocados no dessecador por $1 \mathrm{~h}$ e pesados.

\section{RESULTADOS}

\subsection{Produtos Obtidos}

Os rendimentos dos produtos das pirólises foram calculados pelas Equações 1, 2 e 3 e estão expostos na Tabela 1. 


$$
\begin{aligned}
& R_{\text {sólido }}=\frac{m_{\text {carvão }}}{m_{\text {inicial }}} \times 100 \\
& R_{\text {líquido }}=\frac{m_{\text {oleo }}}{m_{\text {inicial }}} \times 100 \\
& R_{\text {gasoso }}=100-\left(R_{\text {sólido }}+R_{\text {líquido }}\right)
\end{aligned}
$$

Tabela 1 - Rendimentos obtidos com a variação de temperatura

\begin{tabular}{|c|c|c|c|}
\hline $\begin{array}{c}\text { Temperatura } \\
\left({ }^{\circ} \mathrm{C}\right)\end{array}$ & $\begin{array}{c}\text { Rendimento } \\
\text { sólido (\%) }\end{array}$ & $\begin{array}{c}\text { Rendimento } \\
\text { líquido (\%) }\end{array}$ & $\begin{array}{c}\text { Rendimento } \\
\text { gasoso (\%) }\end{array}$ \\
\hline \hline 400 & 37,17 & 45,10 & 17,73 \\
\hline 500 & 31,26 & 50,01 & 18,73 \\
\hline 600 & 29,00 & 51,50 & 19,50 \\
\hline 700 & 27,71 & 53,88 & 18,41 \\
\hline
\end{tabular}

O rendimento em carvão (sólido) diminuiu gradativamente com a elevação da temperatura, enquanto o rendimento em bio-óleo (líquido) aumentou, justificado pela liberação de uma maior quantidade de compostos voláteis. O rendimento gasoso cresceu inicialmente, mas em seguida apresentou uma queda em seu valor, isso ocorreu por esse rendimento ser obtido de forma numérica e não quantitativa.

\subsection{Análises Realizadas}

Após a conversão da biomassa em biocarvão fez-se necessário analisar as características desse produto e a influência da temperatura no mesmo.

- $\quad \mathrm{pH}$

Os valores de $\mathrm{pH}$ obtidos estão expostos na Tabela 2.

Tabela 2 - Valores de $\mathrm{pH}$ dos carvões de diferentes temperaturas

\begin{tabular}{|c|c|c|c|c|}
\hline $\begin{array}{c}\text { Temperatura } \\
\left({ }^{\circ} \mathrm{C}\right)\end{array}$ & 400 & 500 & 600 & 700 \\
\hline \hline Amostra 1 & 7,88 & 8,33 & 8,72 & 8,00 \\
\hline Amostra 2 & 7,73 & 8,30 & 8,73 & 8,21 \\
\hline Amostra 3 & 7,80 & 8,26 & 8,77 & 8,18 \\
\hline Média & $7,81 \pm 0,06$ & $8,30 \pm 0,04$ & $8,74 \pm 0,03$ & $8,13 \pm 0,11$ \\
\hline
\end{tabular}

O aumento de temperatura acarretou na elevação da basicidade do carvão até $600{ }^{\circ} \mathrm{C}$, com um leve decréscimo nos carvões de $700{ }^{\circ} \mathrm{C}$. Para todas as temperaturas analisadas o biocarvão do endocarpo do coco apresentou características básicas, com resultados próximos à média.

\section{- $\quad$ FT-IR}

As curvas correspondentes ao FT-IR dos carvões a diferentes temperaturas são apresentadas na Figura 1. Segundo Choudhury et al. (2014), as vibrações de alongamento das ligações $\mathrm{O}-\mathrm{H}$ presente nos grupos hidroxila estão indicadas pelo pico na região próxima a $3400 \mathrm{~cm}^{-1}$ e em torno de $1700 \mathrm{~cm}^{-1}$ as ligações $\mathrm{C}=\mathrm{O}$ se alongam, em compostos como cetonas e carbonilas. $\mathrm{O}$ pico da região de $1580 \mathrm{~cm}^{-1}$ indica estruturas aromáticas como $\mathrm{C}=\mathrm{C}$ e $\mathrm{C}=\mathrm{N}$. 
Na região de $1000 \mathrm{~cm}^{-1}$ ocorre o alongamento e deformação das ligações $\mathrm{C}-\mathrm{O}$, em compostos como o etanol e entre $700 \mathrm{~cm}^{-1}$ e $400 \mathrm{~cm}^{-1}$ ocorre o alongamento das ligações C-C.

Figura 1 - FT-IR do endocarpo do coco.

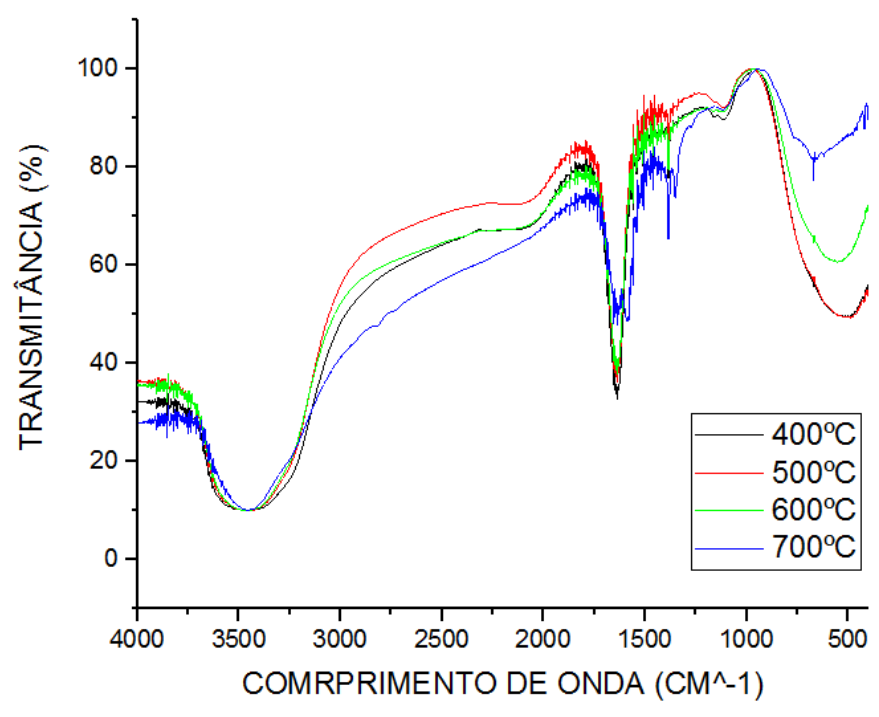

- $\quad$ Análise Imediata

A análise imediata abrange a determinação de umidade, material volátil, cinzas e carbono fixo. As Equações 4, 5, 6 e 7 foram utilizadas para obtenção dos dados expostos na Tabela 3.

$$
\begin{aligned}
& \text { Umidade }_{(\%)}=\frac{m_{\text {seco ao ar_- }} m_{\text {seco a } 105^{\circ} \mathrm{C}}}{m_{\text {seco ao ar }}} \times 100 \\
& \text { Voláteis }_{(\%)}=\frac{m_{\text {seco a } 105^{\circ} \mathrm{C}-} m_{\text {seco } a 950^{\circ} \mathrm{C}}}{m_{\text {seco a } 105^{\circ} \mathrm{C}}} \times 100 \\
& \text { Cinzas }_{(\%)}=\frac{m_{\text {seco pós } 750^{\circ} \mathrm{C}}}{m_{\text {seco a } 105^{\circ} \mathrm{C}}} \times 100 \\
& \text { Carbono Fixo }_{(\%)}=100-\left(\text { Voláteis }_{(\%)}+\text { Cinzas }_{(\%)}\right)
\end{aligned}
$$

Analisando os valores obtidos percebe-se que a umidade não apresentou um comportamento bem definido para a biomassa analisada, variando de acordo com a temperatura. A quantidade de voláteis decresceu com o aumento de temperatura, esse comportamento era esperado, pois, de acordo com Joseph et al. (2009) os voláteis compõem a porção de massa do material liberada durante as pirólises, e quanto mais alta a temperatura utilizada, mais facilmente são liberados. O teor de cinzas consiste na porção que resta após a volatilização dos elementos orgânicos, percebe- se que o endocarpo do coco apresentou baixos teores de cinzas, que aumentaram com a temperatura. O carbono fixo é a porção do material mais resistente, a que permanece após a saída da umidade, voláteis e cinzas, para a biomassa estudada a quantidade desse material aumentou com a temperatura. 
Tabela 3 - Dados da análise imediata para os carvões do endocarpo do coco

\begin{tabular}{|c|c|c|c|c|c|}
\hline & $\begin{array}{c}\text { Temperatura } \\
\left({ }^{\circ} \mathrm{C}\right)\end{array}$ & 400 & 500 & 600 & 700 \\
\hline \hline \multirow{3}{*}{ Umidade (\%) } & Amostra 1 & 3,83 & 3,44 & 4,83 & 1,77 \\
\cline { 2 - 6 } & Amostra 2 & 3,71 & 3,37 & 4,60 & 1,82 \\
\cline { 2 - 6 } & Média & $3,77 \pm 0,09$ & $3,40 \pm 0,05$ & $4,71 \pm 0,16$ & $1,79 \pm 0,04$ \\
\hline \multirow{3}{*}{ Voláteis (\%) } & Amostra 1 & 98,13 & 95,41 & 94,33 & 90,77 \\
\cline { 2 - 6 } & Amostra 2 & 98,14 & 96,71 & 92,62 & 87,97 \\
\cline { 2 - 6 } & Média & $98,13 \pm 0,01$ & $96,06 \pm 0,92$ & $93,47 \pm 1,21$ & $89,37 \pm 1,98$ \\
\hline \multirow{3}{*}{ Cinzas (\%) } & Amostra 1 & 1,20 & 1,41 & 1,50 & 1,61 \\
\cline { 2 - 6 } & Amostra 2 & 1,05 & 1,57 & 1,29 & 1,93 \\
\cline { 2 - 6 } & Média & $1,12 \pm 0,11$ & $1,49 \pm 0,11$ & $1,39 \pm 0,15$ & $1,77 \pm 0,23$ \\
\hline \multirow{2}{*}{$\begin{array}{c}\text { Carbono Fixo } \\
(\%)\end{array}$} & Amostra 1 & 0,67 & 3,18 & 4,17 & 7,62 \\
\cline { 2 - 6 } & Amostra 2 & 0,81 & 1,72 & 6,09 & 10,10 \\
\cline { 2 - 6 } & Média & $0,74 \pm 0,01$ & $2,45 \pm 1,03$ & $5,13 \pm 1,36$ & $8,86 \pm 1,75$ \\
\hline
\end{tabular}

\section{CONCLUSÕES}

O endocarpo do coco foi convertido a uma proporção satisfatória em biocarvão, a qual reduziu com o aumento da temperatura. De modo contrário, a quantidade de bio-óleo aumentou diretamente com a temperatura, sendo alcançados rendimentos maiores deste produto do que do carvão. Os carvões analisados apresentaram diferentes resultados quantitativos para suas propriedades para as diferentes temperaturas analisadas, comprovando que essa variável influencia diretamente na qualidade dos produtos obtidos. Apesar disso, todos os carvões apresentaram características semelhantes.

O biocarvão do endocarpo do coco apresentou comportamento alcalino, que cresceu até determinada temperatura, o que comprova a possibilidade de adição desse material ao solo para reduzir a acidez. Os compostos existentes nos carvões foram localizados através das curvas de espectroscopia obtidas, sendo praticamente iguais nas temperaturas analisadas.

Os carvões produzidos possuem a maior parte da sua composição formada por compostos voláteis, estando de acordo com os altos rendimentos líquidos das pirólises, visto que é resultado da condensação de parte do material volátil. Além disso, apresentaram baixos teores de cinzas e carbono fixo, que se elevaram com a temperatura.

\section{NOMENCLATURA}

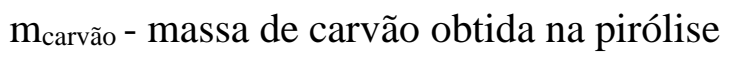

móleo - massa de bio-óleo obtida na pirólise

$\mathrm{m}_{\text {inicial }}$-massa de biomassa inicial

$\mathrm{m}_{\text {seco a }} 105^{\circ} \mathrm{C}$ - massa de carvão após permanecer na mufla a $105^{\circ} \mathrm{C}$ 


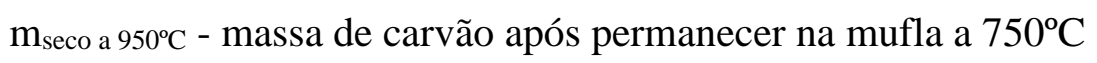

$\mathrm{m}_{\text {seco ao ar }}$ - massa de carvão pesada inicialmente

$\mathrm{m}_{\text {seco pós }} 750^{\circ} \mathrm{C}$ - massa de carvão após permanecer na mufla a $750^{\circ} \mathrm{C}$

Rgasoso - Rendimento gasoso

$\mathrm{R}_{\text {líquido }}$ - Rendimento líquido

$\mathrm{R}_{\text {sólido }}$ - Rendimento sólido

\section{REFERÊNCIAS}

ALHO, C. F. B. V. Efeito da temperatura final de pirólise na estabilidade de biocarvão produzido a partir de madeira de Pinus sp. e Eucalyptus sp. Dissertação de Mestrado. Seropédica, Rio de Janeiro. 2012.

CANTRELL, K. B. et al. Impact of pyrolysis temperature and manure source on physicochemical characteristics of biochar. Bioresource Technology, Essex, v. 107, p. 419-428, Mar. 2012.

CHOUDHURY; DEV, N.; SINGH, C. R.; THALLADA, B.; RUPAM, K. Pyrolysis of jute effect of reaction parameters and analysis of products. The Journal of material cycles and waste managment, vol. 16, p. 449-459, 2014.

HOSSAIN, M. K. et al. Influence of pyrolysis temperature on production and nutrient properties of wastewater sludge biochar. Journal of Environmental Management, New York, v. 92, n. 1, p. 223-228, Jan. 2011.

JOSEPH, S.; PEACOCKE, C.; LEHMANN, J.; MUNROE, P. Developing biochar classification and test methods. In: LEHMANN, J.; JOSEPH, S. (Ed). Biochar for environmental management science and technology. New York: Earthscan, 2009. p. 107-126. 